\title{
The Free Provision of ARV Therapy: \\ Is it a Golden Opportunity on a Silver Platter for Organisations?
}

Brothers K. W. Malema ${ }^{1}$ and Steven F. Koch ${ }^{2}$

\begin{abstract}
This article seeks to establish the extent to which organisations in Botswana are trying to promote the utilisation of government provided ARV service within their workplace, by referring their employees to it. To determine the degree of association between the dependent and predictor variables, Chi square and logit regressions are used. The Botswana AIDS Impact Survey Two (BAIS II) data for workplaces has been used. The degree of referral is quite low amongst both the pubic and privatel parastatal sector organisations. Overall there were 23.7 percent of organisations with referral mechanisms for antiretroviral therapy within the workplace, of which the majority of them had educational programmes of some kind. There is a significant positive relationship between the availability of ARV referral mechanism as the dependent variable and the following predictor variables, namely policy availability and a combination of programmes (ProgIndex). Large organisations have a negatively significant relationship with the dependent variable. There is a need for programmes such as peer educators and HIV/AIDS coordinators and HIV policies to be put in place within workplaces in an effort geared towards minimising losses within organisations.
\end{abstract}

\section{Introduction}

On both the economic and humanitarian front, measures to fight HIV/AIDS and to provide services such as antiretroviral (ARV) therapy are necessary in the workplace. Such measures, though deemed necessary, may be very costly for individual organisations to undertake. The Botswana government with the assistance of global partners has rolled out HIV/AIDS-related services, such as free ARV therapy, free voluntary testing services (VCT) and free services for sexually transmitted infections. Organisations need to utilise these services, since they are available at low cost, by putting referral mechanisms for their workers in place. These steps will ensure an increased utilisation of publicly provided services, and simultaneously improve productivity within the workplace without adversely affecting profits, as would have been the case if organisations provided these services directly. The free provision of ARV therapy accords organisations a golden opportunity, which, if effectively utilised, can mitigate the adverse effects of HIV/AIDS on profitability and ensure an uninterrupted smooth flow of labour services.

The aim of this article is to consider the extent to which the government's freely provided ARV therapy services are being used by firms and other organisations.

1. Doctoral candidate, Economics Department, University of Pretoria and Lecturer, Economics Department University of Botswana. Correspondence; malemabw@mopipi. ub.bw.

2. Professor of Economics, Department of Economics, University of Pretoria, Pretoria 0002, Republic of South Africa; (E) steve.koch@up.ac.za. 
The availability of referral mechanisms, within the workplace, is an indicator of the underlying commitment of an organisation to keep its workforce healthy and in place, during an epoch of extensive HIV/AIDS related illness. The availability is also a prudent economic step, with the potential to ensure continued positive returns for individual organisations and economic growth for the national economy.

The remainder of the paper is organized as follows. A brief review of the relevant literature is provided in the succeeding section. The study's methodology, and the data used in the analysis are described in the third section. The analytical results are presented in Section 4, and the study is concluded in Section 5.

\section{Review of Literature}

ARV therapy has brought people back from the final stages of illness to become active and productive members of society. In the United States, it is estimated that 90 percent of HIV positive individuals are economically active, a number that is expected to rise with advances in medical treatment (Lau and Wong, 2001). Its success in developed countries has created pressure for policy makers in developing countries to provide ARV drugs for their own populations (Forsythe, 1998). The dilemma faced by policy makers is that these drugs are very expensive, and, therefore, exert severe financial pressure on meager resources: buying them may deny preventive and treatment services for those with other illnesses. It is, therefore, necessary to ensure that ARV therapy is sustainable and cost effective, particularly in light of the fact that the cost per patient is high. In Costa Rica, costs amounted to $\$ 7000$ per year after discount (Forsythe, 1998), although that price is higher than the annual $\$ 1500$ per patient expenditure in Botswana in 2000 (Korte, Mazonde and Darkoh; 2004). Fortunately, the costs are trending downward: from US\$10 000 in 1989 to US\$2 738 in 1999 per patient, even though the treatment is evolving over time (Floyd and Gilks, 1998). The lack of political commitment by industrialised nations is another impediment to the provision of ARVs to infected people living in developing countries (Walkowiak, 1999).

When considering the national provision of ARVs within countries, a number of questions need to be answered. These questions seek to determine if provision of ARVs is a human right, if insurance should include AIDS treatment amongst required services, if pharmaceutical companies should discount ARV prices for the poor in developing countries and if international donors have a moral obligation to assure the availability of such drugs globally (Forsythe, 1998). The rationale for the provision of such drugs to poor communities within the developed world has been questioned (Bangsberg, Tulsky, Hecht and Moss, 1997). In some African countries, the call for the provision of drugs for people living with AIDS has been made on political, ethical and human-rights grounds, while those opposed to such a call point to the economic realities of the continent, which makes such an undertaking untenable (Forsythe, 1998).

It is possible, however, that the use of ARVs may reduce costs associated 
with the delivery of other health services, though it is not clear if they are large enough to offset the cost of ARVs. In particular, the use of ARVs is likely to reduce some other treatment costs. Some studies have found that there is a decline in non-ARV drug needs, the duration of hospitalisation, inpatient and outpatient services, deaths and new AIDS cases (Forsythe, 1998). In Brazil, there have been positive financial benefits in excess of US\$ 200 million, due to savings in outpatient and hospital costs resulting from the implementation of antiretroviral programme (Teixeira, Vitoria and Barcarolo, 2003). The use of ARVs may also result in a decline in the levels of HIV within semen, which would further reduce the probability of infection. The counterargument, though, is that the life span of people living with AIDS will increase, and, thus, people, irrespective of their HIV status, may take risks which have the potential of increasing new infections (Forsythe, 1998).

Brazil is the first developing country to implement a universal antiretroviral programme which covered about 125000 people, who represented virtually all those who needed treatment; this represents a third of all those who are thought to need treatment in the developing world (Teixeira, Vitoria and Barcarolo, 2003). The Brazilian initiative, the authors attribute to concerted multi-sectoral approach and the upholding of human rights.

The Botswanan government, which was the first in Africa to provide ARV therapy to all its citizens, rolled-out antiretroviral therapy within the public healthcare system in January 2002 (Noble R., 2006, Medical News Today, 2004). Within three years, over 34000 people were enrolled representing 9 percent of all people on ARV therapy within the developing countries (Medical News Today, 2004). It is estimated that of the over 34000 people, 27 000 people are enrolled under the government Masa (dawn) programme and 7 500 are receiving treatment within the private sector. Those enrolled in ARV therapy are now estimated at 74000 . However, current roll-out runs short of the estimated 110000 people who are in immediate need, amongst the estimated 300000 infected people (Rory, 2004). It was anticipated that 260 000 would be in need of ARV therapy by 2005 , assuming that all people were treated as soon as they were clinically eligible, an assumption undermined by the fact that most people did not know their HIV status (Korte, Mazonde and Darkoh, 2004). Currently, there were 29 operating sites in Botswana, out of the targeted 32 sites country wide. These sites are administering ARV therapy. In the capital, Gaborone, the centre for ARV therapy, probably the largest antiretroviral clinic in the world, 7300 patients were treated and daily enrolment stood at 20 (Rory, 2004).

The rapid expansion of ARV therapy is attributed to many factors, amongst which are the experience and the commitment of health workers as they gain confidence, the overcoming of organisational problems and increased routine testing. To promote awareness about the availability and effectiveness of ARV therapy, a social mobilisation campaign was launched, which also helped to reduce stigma and discrimination. The Masa programme also expanded because of governmental financial support, as well as additional support from 
other stakeholders such as the Global Fund, charities, and non-governmental organisations. Botswana, unlike many other sub-Saharan African countries, has money, better infrastructure and a sounder health system; therefore, it has been able to overcome, for instance, its shortage in trained staff, by setting up a training programme with assistance from the Harvard AIDS Initiative (Noble, 2006).

\section{Methodology}

The study uses BAIS II data from the central statistics office of the ministry of finance of the Botswana government. The sampling frame was based on the latest census conducted in 2001. There were 416 organisations interviewed from both the rural and urban areas as well as from the public and private/parastatal sectors. The investigative tools of analysis are the chisquare measure of association, the logit regression and the corresponding marginal effects derived from the logit regression. The regression analysis is based on a number of independent variables, which are believed to have a bearing on the binary dependent variable, which is the presence (coded as a one) or absence (coded as a zero) of ARV therapy referral services.

In light of HIV/AIDS and its economic impact on profits, some organisations such as Debswana resolved to provide antiretroviral treatment for their employees. A decision made partly as a result of observed high morbidity and mortality rates within their workforce. The impact of the antiretroviral programme was favourable and is considered a success within business circles (UNAIDS, 2002). The available medical Aid schemes within the country also have HIV/AIDS related benefits, while some companies have agreed to pay extra premiums to ensure that their employees enjoy the full advantage of the available HIV/AIDS treatment. Debswana enjoys some financial power, unmatched by the majority of the Botswanan enterprises; therefore, many of other businesses are less likely to emulate Debswana's undertaking. These other enterprises are, however, adversely affected by the epidemic, such that the free provision of ARVs by government offers them the opportunity to do what they might otherwise not have been able to do, even if willing. To this end, the analysis seeks to determine which factors are likely to effect the promotion of the government's freely provided service within the workplace.

The regression is of the form

$$
\operatorname{prob}(\mathrm{w}=1 \mid x)=\Lambda\left(\sum_{i=1}^{n} \mathrm{~b}_{i} x_{i}\right)
$$

Where $w$ is the binary independent variable regarding the existence of ARV therapy referrals, while $\Lambda$ is the logistic probability function. Finally, $\beta$ is a vector of coefficients to be estimated, while $x$ is a matrix of explanatory variables, including the area of the firm, the size of the firm, the gender of the employee, the sector in which the firm resides, an index of available programmes, the policy, the occupation of the worker, and an HIV screening programme. 


\section{Results}

The chi-square results in Table 1 show organisations, divided by economic activity, in line with the national income accounts and whether or not they have ARV therapy referrals in the workplace. The results show that public administration has a higher proportion of organisations with ARV therapy referrals followed by education. Organisational characteristics, such as the availability of HIV educational programmes, HIV coordinators, HIV peer educators and HIV policies were analyzed to establish their association with the availability of ARV therapy referrals. Organisations with these attributes performed better than those without the characteristics, even though such performances are also unsatisfactory.

ARV referral services were under-provided, as 31.5 percent of organisations with a policy provided them, compared to 15 percent for those without a policy. Organisations in the wholesale/retail trade and manufacturing sectors of the economy were performing unsatisfactorily at 13.3 and 14.7 percent, respectively. The education sector had 17.1 percent of organisations, with this service and public administration had 32.9 percent, whereas all other sectors had 35.5 percent of their organisations with ARV referrals.

Table 1: Organisational characteristics associated with having ARV therapy referrals at work

\begin{tabular}{|c|c|c|c|c|}
\hline Characteristics & $\begin{array}{l}\text { Yes to availability } \\
\text { of ARV referrals ( } \\
402<n<410) \%\end{array}$ & $\chi^{2}$ & df & $\begin{array}{l}\mathbf{P}- \\
\text { Value }\end{array}$ \\
\hline $\begin{array}{l}\begin{array}{l}\text { Economic Activity } \\
(\mathrm{n}=409)\end{array} \\
\text { Wholesale/Retail } \\
\text { Manufacturing } \\
\text { Public administration } \\
\text { Education } \\
\text { Others }\end{array}$ & $\begin{array}{l}14.7 \\
13.3 \\
32.9 \\
17.1 \\
35.5\end{array}$ & 19.416 & 4 & 0.001 \\
\hline $\begin{array}{l}\text { Availability HIV/ } \\
\text { AIDS Educational } \\
\text { Programmes }(n=408) \\
\text { Yes } \\
\text { No }\end{array}$ & $\begin{array}{l}30.2 \\
11.4\end{array}$ & 17.926 & 1 & 0.000 \\
\hline $\begin{array}{l}\text { Availability of HIV/AIDS } \\
\text { Coordinator }(n=404) \\
\text { Yes } \\
\text { No }\end{array}$ & $\begin{array}{l}28.6 \\
16.6\end{array}$ & 7.458 & 1 & 0.006 \\
\hline $\begin{array}{l}\text { Availability of HIV/AIDS } \\
\text { Peer Educators }(n=404) \\
\text { Yes } \\
\text { No }\end{array}$ & $\begin{array}{l}29.8 \\
14.8\end{array}$ & 11.952 & 1 & 0.001 \\
\hline $\begin{array}{l}\text { Availability of HIV/AIDS } \\
\text { policy }(n=407) \\
\text { Yes } \\
\text { No }\end{array}$ & $\begin{array}{l}31.5 \\
15.2\end{array}$ & 14.833 & 1 & 0.000 \\
\hline
\end{tabular}

The regression results in Table 2 show a significant positive relationship between ARV therapy referrals as a dependent variable and policy, ProgIndex4 
and ProgIndex3 (A measure of the intensity of programme combinations, with a maximum of four, when all the four programmes are in place and zero if there is no programme) at a 5\% level of significance for the first two and $10 \%$ significance for the latter. Organisations which had at least three programmes in place were more likely to have ARV therapy referrals than those with no programme (ProgIndex0) at all. The correlation between ARV therapy referrals and the government (sector) is negative at $1 \%$ significance. Firm size was categorised into three: small, medium and large firms, where small firms serve as a reference point. In our results, we observe that large firms are less likely to have ARV therapy referrals relative to small firms at a $1 \%$ level of significance. The model is free of specification errors and fits the data well as per the link test and goodness-of-fit test. The model has a correct classification level of $75.4 \%$.

Table 2: Logit estimates for determinants of availability of ARV referrals in the workplace.

\begin{tabular}{|l|c|c|c|}
\hline \multicolumn{1}{|c|}{$\begin{array}{c}\text { Predictor } \\
\text { Variables }\end{array}$} & Coefficients & $\mathbf{Z}$ & P>Value \\
\hline Area & .1230782 & 0.43 & 0.666 \\
\hline Total Employees & -.0002477 & -0.50 & 0.614 \\
\hline $\begin{array}{l}\text { Firmsize } \\
\text { Small Omitted }\end{array}$ & & & \\
Medium & -.2339108 & -0.75 & 0.452 \\
Large & -.776199 & -2.12 & $0.034^{* *}$ \\
\hline gender & .0143706 & 0.48 & 0.632 \\
\hline sector & -.8754805 & -2.69 & $0.007^{* * *}$ \\
\hline ProgIndex & & & 0.705 \\
ProgIndex0 & & -0.38 & 0.499 \\
omitted & -.2139354 & 0.68 & $0.094^{*}$ \\
ProgIndex1 & .3806398 & 1.68 & $0.017^{* *}$ \\
ProgIndex2 & .9127004 & 2.40 & $0.019^{* *}$ \\
ProgIndex3 & 1.351873 & & $0.000^{* * *}$ \\
ProgIndex4 & & & \\
\hline Policy & .7637904 & -3.54 & \\
\hline constant & -1.49051 & & \\
\hline Number of obs $=$ & 358 & & \\
LR chi2(8) & 32.50 & & \\
Prob > chi2 & $=.0006$ & & \\
Pseudo R2 & 0.0801 & & \\
\hline
\end{tabular}

$* *=5$ percent and $* * *=1$ percent significant levels

Table 3 gives us the marginal effects, which measures the percentage changes in the probability of having ARV therapy referrals resulting from a change in one of the independent variables. We note that the independent variables, which are significant in the regression equation, are also significant in the marginal effects save for ProgIndex3. The organisations which adopted 
HIV policies increased the probability of having an ARV therapy referral mechanism by 13.2 percent. As for those which had a combination of all the programmes, the chance of having the referrals was 27.8 percent relative to having no programmes at all. On the other hand, being in the public sector would reduce the likelihood of having ARV therapy referrals by 16.4 percent and an increase in organisational size would reduce the probability of a large firm having ARV referrals by 12.6 percent, relative to a small firm.

\section{Table 3: Marginal Effects}

\begin{tabular}{|l|c|c|c|}
\hline \multicolumn{1}{|c|}{$\begin{array}{c}\text { Predictor } \\
\text { Variables }\end{array}$} & dARV/dx & $\mathbf{Z}$ & P>Value \\
\hline Area & .0221814 & 0.43 & 0.669 \\
\hline Total Employees & -.0000441 & -0.51 & 0.613 \\
\hline Firmsize & & & \\
Small Omitted & & & \\
Medium & -.0407705 & -0.77 & 0.442 \\
Large & -.1255747 & -2.36 & $0.018^{* *}$ \\
\hline gender & .0025599 & 0.48 & 0.632 \\
\hline sector & -.1639712 & -2.61 & $0.009^{* * *}$ \\
\hline ProgIndex & & & \\
ProgIndex0 omitted & & & 0.692 \\
ProgIndex1 & -.0365874 & -0.40 & 0.524 \\
ProgIndex2 & .0722909 & 0.64 & 0.115 \\
ProgIndex3 & .1770036 & 1.57 & $0.026^{* *}$ \\
ProgIndex4 & .277995 & 2.22 & $0.014^{* *}$ \\
\hline Policy & .1315605 & 2.45 & \\
\hline
\end{tabular}

$* *=5$ percent and $* * *=1$ percent significant levels

Organisations generally faired poorly in their referral missions, irrespective of whether they had policies or not. However, the firms with a policy have continued to do relatively better. Organisations with a combination of programmes also faired better than those without programmes.

Manufacturing and wholesale/retail trade sectors are doing very little in the way of promoting the use of government services, through referrals for their employees. Large organisations provide relatively fewer ARV referrals than small firms, which might be because the bigger organisations are providing these services within their setups, and, therefore, are under minimal obligation to refer their employees for additional services. Unfortunately, the present study did not ask for information regarding the provision of such services within organisational setups. The government sector is doing little, if anything at all, to promote ARV referrals in the workplace. More specifically, being in the government sector seems to be a deterrent to having ARV referral services. However, the availability of a combination of programmes (ProgIndex) and policies positively influences the availability of ARV referrals. 


\section{Conclusions and Recommendations}

The government of Botswana, with the assistance of international partners, has carried out an offensive against HIV/AIDS, through the availing of free antiretroviral therapy. The optimal utilisation of this service requires other stakeholders to refer their employees to them. The majority of organisations, however, are not referring their employees for this service, which might will lead to underutilisation of this service and most probably has adverse consequences on the profitability of organisations, economic growth and the general health of the nation. However, it should be borne in mind that there are some other avenues outside the workplace that also dispense information regarding ARV services, and these may promote the service, but limit actual workplace referrals.

Combinations of programmes should be encouraged within organisations, as they have a positive effect on promoting referrals, assuming that referrals keep costs down and profits up. The manufacturing sector, earmarked for diversification, is not making an adequate effort to provide the correct platform for the referral of its employees. It is important to encourage this sector, along with wholesale/retail trade industries to be proactive in fighting HIV and AIDS. Overall, our results suggest that organisations are not utilising the golden opportunity, presented by government, to improve worker health at limited cost, and, thus raise profits. Further research to establish factors behind this observation is still needed.

\section{References}

Bangsberg, D., Tulsky, J. P., Hecht, F. M. and Moss, A. R., 1997 "Protease Inhibitors in the Homeless." Journal of the American Medical Association, Vol. 278 (1): 63-65.

Floyd, K. and Gilks, C. 1998. Cost and Financing Aspects of Providing Anti-Retroviral Therapy: A Background Paper

Forsythe, S. S. 1998. The Affordability of Antiretroviral Therapy in Developing Countries: What Policy Makers need to know. Policy unit of AIDSCAP/Family Health International.

Korte, D., Mazonde, P. and Darkoh, E. 2004. Perspectives and Practice in Antiretroviral Treatment: Introducing ARV Therapy in the Public Sector in Botswana. Case Study. WHO, Geneva

Lau, J. T. F. and Wong W. S. 2001. AIDS-related discrimination in the workplace-the results of two evaluative surveys carried out during a three-year period in Hong Kong. AIDS CARE, Vol. 13 (4): 433-440.

Medical News Today, 2006. Botswana's ARV National Roll-Out Complete in All Hospital. http://www.medicalnewstoday.com/medicalnews.php/newsaid/17060\&nfid/rssffeeds

Noble, R. 2006. HIV \& AIDS in Botswana. http://www.avert.org/aidsbotswana.htm

Rory, C. 2004. Botswana: A beacon of hope in Africa. The Guardian, 15 July, 2004

Teixeira, P. R., Vitoria, M. A. and Barcarolo, J. 2003. The Brazilian Experience in Providing Universal Access to Antiretroviral Therapy

UNAIDS (2002). The private sector responds to the epidemic: Debswana-a global benchmark. Geneva: UNAIDS 
Walkowiak, H. A. 1999. Improving access to antiretroviral drugs in developing countries: constraints and strategies. Msc Dissertation. London School of Hygiene and Tropical Medicine, London, UK 